\title{
Cognitive benefits of sleep and their loss due to sleep deprivation
}

\author{
Jeffrey M. Ellenbogen, MD
}

W hen Nobel laureate Otto Loewi discovered the chemical basis of neurotransmission in 1921, he attributed his experimental design to an insight he made during sleep. ${ }^{1}$ In recent years, scientific discoveries have begun to empirically validate the hypothetical role of sleep in cognitive processes such as insight formation and memory consolidation. Yet these new and important scientific findings-that sleep benefits cognition-have gained little attention in the debates over regulating resident work hours.

In this article, I aim to achieve three goals: First, I will show that sleep deprivation causes two independent negative consequences to cognition: a detriment and a loss of benefit; I will explain this distinction. Second, I will briefly review evidence supporting sleep's benefits for cognition. Finally, I will argue that these benefits of sleep for cognition provide novel reasons why depriving residents of sleep is inconsistent with our ethical standards and educational goals for medical training. In this final section, I will also argue against the assertion that residents should use performance-enhancing medications to overcome the effects of sleep deprivation.

\section{Sleep loss: Distinguishing detriments from loss of benefits}

Sleep loss causes profound impairments in cognitive and behav- ioral performance. For example, in a prospective, randomized study looking at the effects of sleep deprivation in residency training, interns working a "traditional schedule" made $36 \%$ more serious medical errors compared with interns under an "intervention schedule" that included more sleep. ${ }^{2}$ Another study demonstrated that traditional-schedule interns had more than twice the rate of attentional failures when compared with the intervention-schedule interns. ${ }^{3}$ Taken together, these studies demonstrate that sleep-deprived house staff make a significant amount of serious medial errors, largely the consequence of attentional failures from sleepiness. These excellent studies provide empirical evidence for the cognitive detriments of sleep loss.

Recently published studies (see below) looking at the benefits of sleep take a different, but complementary, approach. They seek to understand the benefits of sleep, rather then the detriments of sleep loss. This is a subtle but important distinction. Instead of studying the negative consequences of sleep loss, these studies seek to understand the positive gains produced by sleep. If these cognitive benefits of sleep exist, then missing sleep would hypothetically deprive a person of them.

Were one not aware of this loss of benefit, poor performance during cognitive testing on the morning following a night of missed sleep would be entirely attributed to the detriments from sleep loss. The missed benefits would go unnoticed. By analogy, if you do not deposit money in a bank, and it is subsequently stolen, your losses may be calculated as the amount of money stolen. However, the real amount of money lost is the quantity stolen, plus that which would have been added had it been in the bank earning interest prior to being stolen.

\section{Evidence supporting cognitive benefits of sleep}

Evidence for a beneficial role of sleep in cognition is rapidly emerging in the cognitive and neuroscience literature. ${ }^{4-8}$ These studies isolate sleep's benefit by comparing a sleep period with a non-sleepdeprived wake period. The paradigm is as simple as it is insightful: control participants train on a cognitive task in the morning and are tested 12 hours later; they are compared with a group that trains at night, sleeps, and is tested 12 hours later.

Walker et al. ${ }^{4}$ performed a study that illustrates the paradigm (figure). There are two groups of participants: the wake-control group and the sleep-experimental group. The wake-control participants engage in a motor-learning task at $10 \mathrm{AM}$, where they practice a particular set of sequences on a keyboard. The last few trials of the training session are taken as a marker of their best performance (speed and accuracy). Next, they 


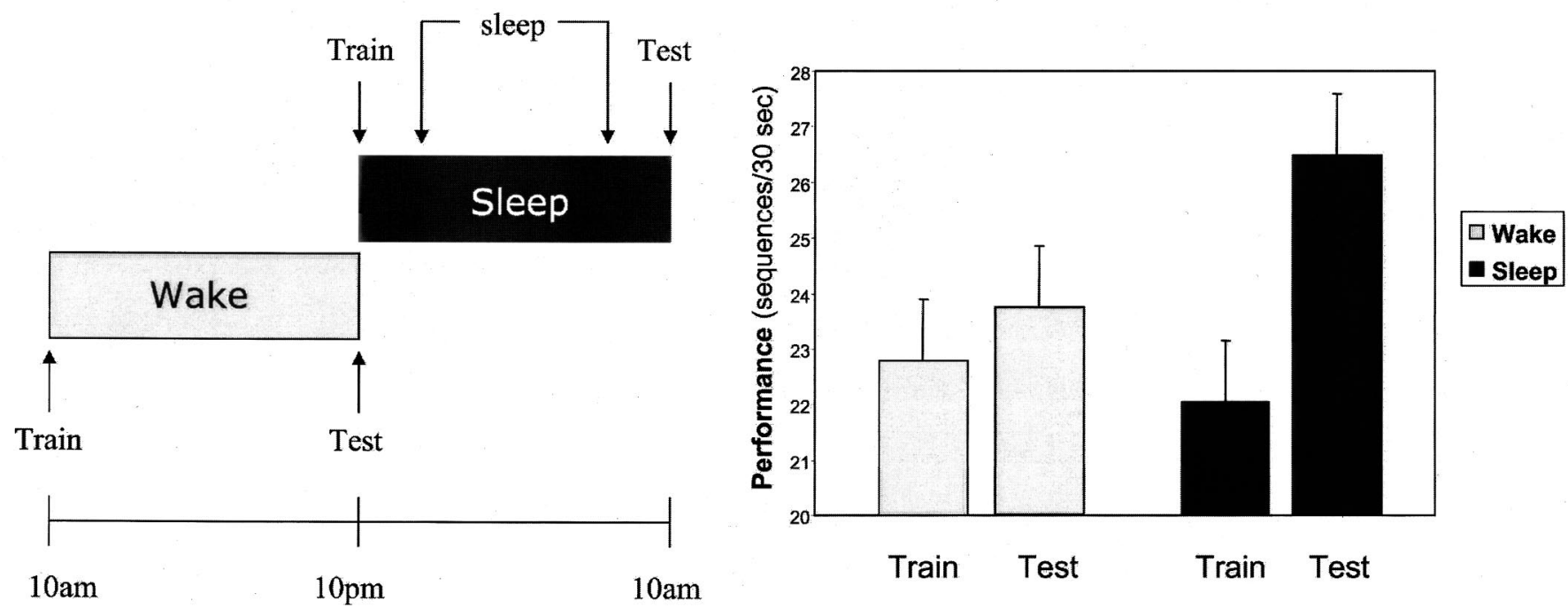

Figure. Exemplary study showing the benefit of sleep for motor learning (adapted from Walker et al. ${ }^{4}$ ). (A) Method. Wake (control) group was trained on a motor-memory task in the morning, and then tested again after 12 hours of wakefulness. Sleep (experimental) group was trained in the evening; then this group was tested in the morning following a night's sleep. (B) Results. Testing after a 12-hour period which contained sleep resulted in a statistically significant improvement in performance when compared to a 12-hour period of wakefulness. Train = performance during the last (and therefore best) trials of training; test = performance on testing 12-hours later, either after a waking day (wake group) pr after a night which included sleep (sleep group).

are tested on the same task at 10 PM (12 hours later). The sleepexperimental participants learn the task at $10 \mathrm{PM}$, sleep overnight, and are tested at $10 \mathrm{AM}$ on the following morning. The sleep group shows significantly greater improvement in performance, from training to testing, when compared with the wake controls. This experimental paradigm has been successfully employed to show the benefit of sleep for several forms of neural processing, including insight formation, ${ }^{5}$ novel-language perception, ${ }^{6}$ visual discrimination, ${ }^{7}$ and motor skills. ${ }^{8}$

There is not universal agreement that sleep benefits cognition. ${ }^{9}$ However, many recently published studies employ improvements in methodology, including avoiding the use of sleep deprivation, and they no longer focus exclusively on REM sleep. These studies provide strong evidence for sleep-dependent cognitive processing.

In addition to the behavioral data, there is also a biologically plausible mechanism for sleep benefiting memory: the hippocampalneocortical dialogue. Simplified, this hypothetical model asserts that, in wakefulness, information is encoded in the hippocampus. During the subsequent slow wave sleep, the encoded memory trace is replayed by the hippocampus; the movement of information between the neocortex and hippocampus then repeats over each sleep cycle. This reiterative process is thought to facilitate consolidation of memory traces. Evidence for the hippocampal-neocortical dialogue already exists in animals, ${ }^{10}$ and translational research looking at declarative (hippocampal-dependent) memory in humans is currently under way.

\section{Performance-enhancing medication for residents}

Some physicians advocate that sleep-deprived residents be required to take medication such as modafinil or more traditional stimulants (including caffeine) to overcome the cognitive and behavioral detriments resulting from sleep loss. There are several serious problems with this proposal: First, no medication is free of side effects. Compelling house staff to consume medication, in order to adequately perform their job, exposes them to these agents' potentially serious risks (known or unknown) or merely unpleasant side effects or both. Second, there are serious ethical concerns raised by employing medications for "performance enhancement," 11 and the medical community is not exempt from such considerations.

Finally (and most relevant for this article), taking medication will-in principle-not recover the benefit sleep has to offer cognition. Even if we hypothetically could safely and completely restore sleepdeprived arousal and attention impairments by administering medication, a memory trace that was not consolidated during a night of lost sleep could not be recovered thereafter.

\section{Conclusion}

If the demands of residency training result in sleep-depriving house staff, this will impair residents' cognitive processing for two independent reasons: detriments and loss of benefits. The detriments 
resulting from sleep loss include impaired cognitive and behavioral performance, partly from diminished attention and arousal. The loss of benefits due to the lack of sleep includes missing sleepdependent cognitive processing such as memory consolidation and insight formation.

Detriments due to sleep loss compromise the health and wellbeing of residents (including placing them at risk for motor vehicle accidents $)^{12}$ and negatively impact the outcome of the patients they are trying so hard to serve., ${ }^{2,3}$ This has recently been demonstrated by a series of rigorous studies and should impact our evidenced-based medical practices and policies.

Sleep deprivation also results in the loss of sleep's benefits for cognitive processes such as memory and insight formation: the building blocks of learning, creativity, and scientific discovery. These losses are also ethically problematic, incompatible with our healthproviding goals, and inconsistent with the educational aspirations of residency training.

\section{References}

1. Mazzarello P. What dreams may come? Nature 2000;408:523.

2. Landrigan CP, Rothschild JM, Cronin JW, et al. Effects of reducing interns' work hours on serious medical errors in intensive care units. N Engl J Med 2004;351:1838-1848.

3. Lockley SW, Cronin JW, Evans EE, et al. Effect of reducing interns' weekly work hours on sleep and attentional failures. N Engl J Med 2004;351:1829-1837.

4. Walker MP, Brakefield T, Morgan A, Hobson JA, Stickgold R. Practice with sleep makes perfect: sleep-dependent motor skill learning. Neuron 2002;35:205-211.

5. Wagner U, Gais S, Haider H, Verleger R, Born J. Sleep inspires insight. Nature 2004; 427:352-355.

6. Fenn KM, Nusbaum HC, Margoliash D. Consolidation during sleep of perceptual learning of spoken language. Nature 2003; 425:614-616.

7. Stickgold R, James L, Hobson JA. Visual discrimination learning requires sleep after training. Nat Neurosci 2000;3:1237-1238.

8. Walker MP, Brakefield T, Hobson JA, Stickgold R. Dissociable stages of human memory consolidation and reconsolidation. Nature 2003;425:616-620.

9. Siegel JM. The REM sleep-memory consolidation hypothesis. Science 2001;294:10581063.

10. Southerland GR, McNaughton B. Memory trace reactivation in hippocampal and neocortical neuronal ensembles. Curr Opin Neurobiol 2000;10:180-186.

11. Wolpe PR. Treatment, enhancement and the ethics of neurotherapeutics. Brain Cogn 2002;50:387-395.

12. Barger LK, Cade BE, Ayas NT, et al. Extended work shifts and the risk of motor vehicle crashes among interns. N Engl J Med 2005;352:125-134. 


\section{Neurology}

\section{Cognitive benefits of sleep and their loss due to sleep deprivation Jeffrey M. Ellenbogen \\ Neurology 2005;64;E25-E27 \\ DOI 10.1212/01.wnl.0000164850.68115.81}

\section{This information is current as of April 11, 2005}

\section{Updated Information \&} Services

References

Citations

Permissions \& Licensing

Reprints including high resolution figures, can be found at: http://n.neurology.org/content/64/7/E25.full

This article cites 12 articles, 1 of which you can access for free at: http://n.neurology.org/content/64/7/E25.full\#ref-list-1

This article has been cited by 1 HighWire-hosted articles: http://n.neurology.org/content/64/7/E25.full\#\#otherarticles

Information about reproducing this article in parts (figures,tables) or in its entirety can be found online at:

http://www.neurology.org/about/about_the_journal\#permissions

Information about ordering reprints can be found online:

http://n.neurology.org/subscribers/advertise

Neurology ${ }^{\circledR}$ is the official journal of the American Academy of Neurology. Published continuously since 1951, it is now a weekly with 48 issues per year. Copyright . All rights reserved. Print ISSN: 0028-3878. Online ISSN: 1526-632X.

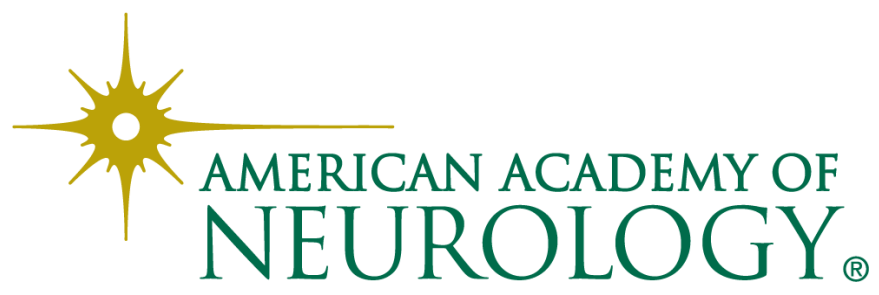

